\title{
Author's reply to commentary on "The role of MRI pelvimetry in predicting technical difficulty and outcomes of open and minimally invasive total mesorectal excision: a systematic review"
}

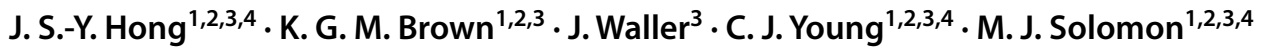

Received: 2 June 2021 / Accepted: 2 June 2021 / Published online: 28 June 2021

(c) Springer Nature Switzerland AG 2021

Dear Dr Martinez-Perez and co-authors of the EuMaRCS Study group,

Thank you for your letter [1] regarding our recent publication [2].

We agree with your statement that the isolated use of pelvimetry measurements to predict surgical difficulty and assist with selecting a surgical approach is an oversimplification and that the EuMaRCS score incorporating anatomical, morphological, patient-related and tumour characteristics is more likely to provide an accurate predictive tool. The EuMaRCS study [3] was discussed in our review, but the scoring [4] system had not been published at the time of our publication.

Our own results [5] utilising MRI pelvimetry measures obtained from patients enrolled in the ALaCaRT study [6] certainly suggest that pelvimetry measures alone are not predictive of successful surgery. However, there was an unexpected finding of an association between larger pelvic volume estimate and unsuccessful surgery. An interesting finding that requires further assessment.

Once again many thanks for your insights.

\section{References}

1. Martínez-Pérez A, Espin E, Pucciarelli S, Ris F, de'Angelis N, on behalf of the EuMaRCS Study Group (2020) Commentary

J. S.-Y. Hong

jonathan.hong@sydney.edu.au

1 Surgical Outcomes Research Centre (SOuRCe), Sydney, Australia

2 The Institute of Academic Surgery at RPA, Sydney, Australia

3 Department of Colorectal Surgery, Royal Prince Alfred Hospital, Sydney, Australia

4 University of Sydney, Sydney, Australia on "The role of MRI pelvimetry in predicting technical difficulty and outcomes of open and minimally invasive total mesorectal excision: a systematic review." Tech Coloproctol. https://doi.org/ 10.1007/s10151-020-02343-1

2. Hong JS, Brown KGM, Waller J, Young CJ, Solomon MJ (2020) The role of MRI pelvimetry in predicting technical difficulty and outcomes of open and minimally invasive total mesorec- tal excision: a systematic review. Tech Coloproctol. https://doi.org/10. 1007/s10151-020-02,274-x

3. de Angelis N, Pigneur F, Martinez-Perez A, Vitali GC, Landi F, Torres-Sanchez T, Rodrigues V, Memeo R, Bianchi G, Brunetti F, Espin E, Ris F, Luciani A, EuMa RCSSG (2018) Predictors of surgical outcomes and survival in rectal cancer patients undergoing laparoscopic total mesorectal excision after neoadjuvant chemoradiation therapy: the interest of pelvimetry and restaging magnetic resonance imaging studies. Oncotarget 9:25315-25331

4. de Angelis N, Martinez-Perez A, Vitali GC, Pigneur F, Luciani A, Brunetti F, Kraft M, Marti-Martinez E, Moroni P, Espin E, Ris F, Pucciarelli S, EuMa RCSSG (2020) Predicting difficult laparoscopic total mesorectal excision for locally-advanced mid- low rectal cancer: the EuMaRCS Score validation. Anticancer Res 40:2079-2087

5. Manuscript submitted.

6. Stevenson AR, Solomon MJ, Lumley JW et al (2015) Effect of laparoscopic-assisted resection vs open resection on pathological outcomes in rectal cancer: the ALaCaRT randomized clinical trial. JAMA 314:1356-1363

Publisher's Note Springer Nature remains neutral with regard to jurisdictional claims in published maps and institutional affiliations. 